Quim. Nova, Vol. 25, Supl. 1, 12-13, 2002.

\title{
A CATÁLISE NO BRASIL NOS ÚLTIMOS 25 ANOS: UMA HISTÓRIA DE SUCESSO
}

\author{
Jairton Dupont
}

Instituto de Química, Universidade Federal do Rio Grande do Sul, Av. Bento Gonçalves, 9500, 91501-970 Porto Alegre - RS

\begin{abstract}
THE CATALYSIS IN BRAZIL: A HISTORY OF SUCCESS IN THE LAST 25 YEARS. In the last 25 years the research in catalysis has passed from heterogeneous processes mainly applied to petrochemical industries to homogeneous processes applied to fine chemicals and green chemistry. In this context the Brazilian Chemical Society (SBQ) is playing an important role in the organization of this interdisciplinary area involving researches from different fields of physical sciences.
\end{abstract}

Keywords: catalysis; history.

É surpreendente constatar que apesar da Catálise estar presente em mais de $85 \%$ de todos os processos industriais de transformação química, somente no início dos anos 1970 começaram a surgir as primeiras atividades de pesquisa em catálise no Brasil. Essas atividades, realizadas em São Paulo e no Rio de Janeiro, em nível acadêmico e industrial, estavam ligadas essencialmente à área de catálise heterogênea aplicada a processos petroquímicos. Essa característica se mantém até hoje como a principal atividade na área de catálise. Os grupos que desenvolvem essas atividades estão, na sua maioria, ligados aos Departamentos de Engenharia como na COPPE-UFRJ e IME (RJ), UNICAMP e UFSCar (SP) e participam ativamente de ações da Comissão de Catálise do IBP (Instituto Brasileiro de Petróleo) e, a partir de 1998, da própria Sociedade Brasileira de Catálise (SBCat). Com o surgimento do Programa Nacional de Catálise (PRONAC) em 1982, grupos emergentes, principalmente na área de catálise heterogênea, puderam se fixar em diferentes regiões do país, tendo como centro das atividades o CENPES-Petrobras, COPPE-UFRJ e UFSCar. Nessa mesma época começaram a surgir os primeiros trabalhos na área de catálise homogênea aplicados à petroquímica, como por exemplo no IQUNICAMP e IQ-UFRGS. No inicio dos anos 1990 deu-se um salto de quantidade e qualidade de grupos que trabalham em catálise homogênea aplicada a materiais poliméricos (Catálise Ziegler-Natta) e na química fina em diferentes regiões do País (UFRJ, UNICAMP, USP, UFBA, UFMG, UFRGS, etc).

Visto a interdisciplinaridade e importância da área tanto em nível acadêmico como industrial, em 1995 alguns sócios da SBQ que realizam atividades relacionadas com a catálise propuseram a criação da Divisão de Catálise visando a organização e o incentivo dessas atividades anteriormente dispersas nas mais diferentes Divisões. Atualmente, a Divisão de Catálise abriga trabalhos das mais distintas áreas da Química como Orgânica, Inorgânica, Físico-Química e Materiais. Desde a criação da Divisão de Catálise o número de trabalhos nas sessões de painéis oscilou entre 30 e 50 , sendo que na $25^{\text {a }}$ Reunião Anual da Sociedade Brasileira de Química um número recorde de quase 70 trabalhos serão apresentados, evidenciando a consolidação e o crescimento da Divisão.

A criação da Divisão de Catálise da SBQ possibilitou um efetivo intercâmbio entre pesquisadores de diferentes áreas os quais apresentam um interesse comum na área: usuários de catalisadores atuantes em síntese orgânica e materiais poliméricos, pesquisadores de síntese inorgânica, potenciais geradores de novos catalisadores, aqueles atuantes na área de caracterização físico-química de precursores catalíticos, na área de novos materiais e pesquisadores atuantes na área de engenharia e bioquímica (biocatálise). Estas interações têm se tornado cada vez mais intensas e hoje em dia o diretor da Divisão de Catálise da SBQ tem assento no Conselho da Sociedade Brasileira de Catálise. Assim, a partir de 1998, a SBQ e a SBCat começaram a promover em conjunto a maioria das ações em catálise no Brasil, sendo esta interação singular no mundo.

Atualmente vários são os Grupos desenvolvendo projetos de pesquisa na área de Catálise no Brasil e não cessa de crescer o número de usuários de catalisadores. A demanda de pessoal altamente qualificado, assim como de conhecimento básico e aplicado vêm aumentando significativamente, principalmente oriundas das necessidades da indústria petroquímica e do setor de Química Limpa que tendem a crescer nos próximos anos, seja pela imposição econômica ou pela adequação à legislação ambiental. É interessante ressaltar que apesar das atividades em catálise serem muito recentes, vários dos grupos atuantes estão entre os mais produtivos e destacados no contexto internacional. Por exemplo, uma pesquisa na WebofScience mostrou que em 2001 foram publicados aproximadamente duzentos artigos relacionados à área de catálise. Dados atualizados de grupos atuantes em Catálise (tanto do setor acadêmico como industrial) assim como da produção científica e tecnológica podem ser obtidos diretamente do Diretório de Grupos de Pesquisa no Brasil, na homepage da SBCat (http://www.ufscar.br/ sbcat) e na página da Divisão de Catálise (http://www.sbq.org.br). O Diretório de Grupos de Pesquisa no Brasil, na sua versão 4.1, apresenta 41 grupos de pesquisa tendo a palavra catálise no seu título. Considerando a palavra catálise não só no título do grupo mas também nas linhas de pesquisa e palavras-chave são encontrados 97 grupos de pesquisa, o que mostra a importância do tema bem como as diferentes competências necessárias para o desenvolvimento de pesquisa numa área tão interdisciplinar e de importância tecnológica estratégica. Também já é hora de introduzirmos a disciplina de Catálise nos currículos dos cursos de graduação e aqui a Divisão de Catálise deve desempenhar um papel fundamental no estabelecimento de discussões na implementação do currículo. Mais uma vez a SBQ desempenha papel fundamental na organização e incentivo das atividades de pesquisa na fronteira do conhecimento. 
APÊNDICE

DIVISÃO DE CATÁLISE

Número de filiados: 87 (atual)

2000-2002

DIRETOR:

Adriano L. Monteiro

VICE-DIRETOR: Eduardo Nicolau dos Santos

TESOUREIRO:

Regina Buffon

1998-2000

DIRETOR:

Jairton Dupont

VICE-DIRETOR:

Maria do Carmo Rangel

TESOUREIRO:

Wagner Ferraresi de Giovani

1996-1998

DIRETOR:

VICE-DIRETOR:

Eduardo Nicolau dos Santos

TESOUREIRO:

Jílio Carlos Afonso

Regina Buffon

1995-1996 (Criação)

DIRETOR:

Wagner Ferraresi De Giovani

VICE-DIRETOR:

Eduardo Nicolau dos Santos 